Original Article

\title{
PREVALENCE OF AUTISM AUTISTIC FEATURES AND ASSOCIATED RISK FACTORS IN SUBJECTS ATTENDING SPECIAL SCHOOLS IN OUR COM MUNITY
}

\author{
Sharda V. ${ }^{1}$, Subbalakshmi N.K. ${ }^{2}$, Narayana S. ${ }^{3}$, Samal R.K. ${ }^{4}$ \\ ${ }^{1}$ Lecturer, Department of Community M edicine, K.S. Hegde M edical Academy, Deralakatte, Mangalore - 575018 , \\ Karnataka, India. ${ }^{2}$ Associate Professor, Department of Physiology, Kasturba M edical College, Light House Hill Road, \\ M angalore - 575 001, Karnataka, India. ${ }^{3}$ National Coach, Special Olympics Bharath, St. Agnes Special School, \\ Mangalore, Karnataka , India. ${ }^{4}$ Professor, Department of Community M edicine, , K.S. Hegde Medical Academy, \\ Deralakatte, Mangalore - 575 018, Karnataka, India
}

Correspondence:

Subbalakshmi N.K.

Department of Physiology, Kasturba M edical College, PO Box 53, Light House Hill Road, Hampanakatta, Mangalore 575001 , Karnataka, India. Mobile : +91 9483910879 Fax: +91 8242428183

E-mail: rao.subbalakshmink@rediffmail.com

\begin{abstract}
:
Introduction : There is no one single unified theory to explain the etiology of autism. Autistic symptoms occur along a wide spectrum. Thus we studied the autistic symptoms according to gender, mental retardation and presence of epilepsy.
\end{abstract}

Methods : 500 children attending different special schools were screened for autism employing DSM -IV diagnostic criteria for autistic disorder. Data was analysed employing suitable statistical tests. P value less than 0.05 was considered significant.

Results : Display of autistic features was significantly different among the study subjects (p value less than 0.00001 ). But more than $90 \%$ of the subjects had distorted speech, repetitive speech and tantrum to minor changes symptoms. Autistic males were two times greater than autistic females (50 vs. 24). Proportion of autistic subjects with loneliness and poor interaction was significantly higher in 26-50 intelligence quotients group compared to 51-80 intelligence quotients ( $p$ value equal to $0.002,0.03$ respectively). $25.67 \%$ autistic subjects were epileptic. In them, prevalence of not identifying strangers, failing to make eye contact, not understanding humor symptoms were significantly higher compared to others ( $p$ value equal to $0.018,0.044,0.015$, respectively). Epilepsy was associated with higher number of autism symptoms ( $p$ value equal to 0.023 ).

Conclusions : Tantrum to minor changes, distorted and repetitive speech are the most common autistic features. Risk of autism is 2 times higher in males compared to females. Aloofness and poor interaction symptoms are higher in autistic subjects with lower intelligence quotients. Epilepsy is associated with higher number of autism symptoms.

Keywords : autism, autism features, mental retardation, epilepsy, gender

\section{Introduction:}

Autism is a complex neurodevelopmental disorder characterized by qualitative impairments in social interaction and communication, with restricted, repetitive, stereotyped patterns of behavior, interests and activities.

${ }^{(1,2)}$ Autism affects information processing in the brain by altering how nerve cells and their synapses connect and organize; how this occurs is not well understood. ${ }^{(3)}$ Diagnosis is based on behavior not cause or mechanism. ${ }^{(4,5)}$ Parents usually notice signs in the first two years of their child's life. ${ }^{(6)}$ The signs usually develop gradually, but some autistic children first develop more normally and then regress. ${ }^{(7)}$ Autistic individuals may have symptoms that are independent of the diagnosis, but that can affect the individual or the family. ${ }^{(8)}$ Although the symptoms of autism and Autism spectrum disorder (ASD) begin early in childhood, they are sometimes missed. A 2009 US study found the average age of formal ASD diagnosis was 5.7 years, far above recommendations, and that $27 \%$ of children remained undiagnosed at age 8 years. ${ }^{(9)}$ Most recent reviews of epidemiology estimate a prevalence of one to two cases per 2,000 people for autism, and about six per 1,000 for ASD. ${ }^{(10)}$ These rates are consistent across cultures and ethnic groups, as autism is considered a universal disorder. ${ }^{(11)}$ A population-based study of one Minnesota County found that the cumulative incidence of 
autism grew eightfold from the $1980-83$ period to the 1995-97 period. The increase occurred after the introduction of broader, more-precise diagnostic criteria, increased service availability, and increased awareness of autism. ${ }^{(12)}$ Nevertheless, information on global incidence of autism is less readily available. Regardless of geography, an increased awareness of autism and factors associated with it can only lead to an increase in diagnosis and better treatment.

A special school is a school catering to the special educational needs of students due to severe learning difficulties, physical disabilities or behavioral problems. Thus, special schools are the most likely place of clustering of subjects with autism. Hence this study was undertaken to estimate the prevalence of autism and associated factors in subjects attending different special schools in our community.

\section{Materials And Methods :}

This study was undertaken after the approval by the Institutional Ethical Committee in accordance with the Ethical Standards laid down in the Declaration of Helsinki and obtaining consent from the study participants. This was a clustered sample study drawn from different special schools in and around Mangalore, Karnataka state, India. 500 special school children were screened for autism employing DSM -IV diagnostic criteria for autistic disorder. ${ }^{(13)}$ The level of intelligence functioning was measured by clinicians trained in this field. Autistic features were gathered by personal interview with parents and class room teachers.

The data analysis was done by employing Chi-square, Cochran's, Fisher's exact, Odds ratio and Students unpaired $t$ test. The various analyses were performed using the Statistical Package for Social Science version 11.0 and Statistical Package for Social Sciences for Windows version 11.0.1. Statistical significance was taken to be at $p$-value less than 0.05 .

\section{Result:}

Prevalence of autism and frequency of autistic features in study group
Out of 500 special school children screened for autistic disorder, 74 were diagnosed with autism (14.8\%). The age of the study subjects ranged from 4 to 37 years; and the mean (and standard deviation) age was $15 \pm 6.64$ years.

Proportion of subjects with different autistic features in the study group is presented in table 1. Display of autistic features were significantly different among the study subjects (Cochran's $Q=77.395, p<0.00001$ ); among the autistic features, distorted speech, repetitive speech and tantrum to minor changes was observed in more than $90 \%$ of the autistic subjects (Table I).

\section{Prevalence of autism and frequency of different autistic features in male and female study groups}

Among the 74 subjects with autism, 50 (67.56\%) were males and 24 (32.43\%) were females. Display of autistic features were significantly different both in male and female groups (Cochran's Q $\quad=52.805, \mathrm{p} \varangle 0.00001$; Cochran's $Q=30.981, p \varangle 0.0001$ respectively).

Proportion of subjects with different autistic features and other associated conditions in the male and female study groups is presented in Table I. Among the autistic features, distorted speech, repetitive speech and tantrum to minor changes were observed in more than $90 \%$ of the male and female study subjects (Table I). There was no significant difference in proportion of subjects with autistic features in male study group compared to female study group (Tablel).

\section{Intelligence quotients (IQ) and its association with autistic features in study group}

The IQ of all the study subjects except of one was less than 70. The IQ of study subjects ranged from 26 to 78 . The mean (and standard deviation) IQ of study group was 46.22 \pm 11 .33. The mean IQ of females was significantly lower compared to male autistic group ( $42.58 \pm 6.827$ vs. $47.98 \pm$ $12.64, p=0.02 . p=0.02$ ).

Based on the intelligence quotients study subjects were divided into two subgroups. The comparison of autistic features between 26-50 and 51-80 IQ is presented in Table

II. Proportion of autistic subjects with loneliness was 
significantly higher in 26-50 IQ group compared to 51-80 IQ group (Fisher exact test 2 sided $p=0.002$ ). Proportion of autistic subjects with good, average and poor interaction was significantly different between 26-50 IQ group and 5180 IQ group ( Pearson Chi-square 6.720, $p=0.035$; Likelihood ratio 7.041, $p=0.030$, Table II).

\section{Prevalence of epilepsy, its association with characteristic features of autism, severity of autism and mental retardation in study subjects}

Among the 74 subjects with autism, 19 also had history of epilepsy (25.67\%). Among these 19 epileptic autistic subjects, $6(25 \%)$ were females and 13 (26\%) were males. Frequency of autistic females with epilepsy was not significantly different compared to male autistics with epilepsy.

The comparison of frequency of autistic features in study subjects with and without epilepsy is presented in Table III. Among the autistic features, proportion of autistic subjects not identifying strangers, failing to make eye contact, not understanding humor and delayed mile stones were significantly higher in epileptic autistic group compared to non-epileptic autistic group ( $p=0.018,0.044,0.015$, 0.046 respectively, Table III).

Each autistic feature was assigned one score. The total scores up to 6 were considered mild, 7-14 as moderate and 15-19 as severe autism. Among the epileptic autistic subjects 10 had moderate and 9 had severe autism. None of the mild autistic group had history of epilepsy. Likelihood ratio probability showed association between epilepsy and severity of autism $(p=0.023)$.

Among the 48 subjects with IQ ranging from 26- 50, 13 were epileptic (27.08\%). Epilepsy was found in 6 (23.07\%) subjects having IQ between51-80. This difference was not statistically significant.

\section{Preferences/ liking of study subjects:}

Other unique features of autistic subjects were considered. All the subjects had liking for a particular food item. Among these 56 (75. 67\%) had liking for a particular sweet item and $10.81 \%$ subjects had liking for a particular fried item. The liking for music was observed in 66 subjects (89. 18\%).

\section{Parental marital and socio-economic status}

The particulars regarding the age of parents, economic status and whether married in relation or not was taken into account. The mean (and standard deviation) maternal age was $30.39 \pm 9.13$ and paternal age was $36.34 \pm 9.65$. Among these parents, 18 were married in relation (24.32\%). The mean (and standard deviation) percapita of parents was Rs. $5674.35 \pm 4279.86$. There was no significant association between symptoms of autism and parental age, married in relation and percapita of parents. There was no significant association between autistic features and married in relation, percapita income and mental retardation or development of seizure.

\section{Discussion :}

Autism prevalence has been estimated at 1-2 per 1,000. ${ }^{(10)} \mathrm{But}$ in the present study, autism was found in $14.8 \%$ of the subjects studied. However, our subjects were drawn from special schools and were not community based. Thus clustering sample from special schools could have resulted in the higher prevalence of autism. Likewise, the fraction of autistic individuals who also meet criteria for mental retardation has been reported as anywhere from $25 \%$ to $70 \% .{ }^{(14)}$

In the present study, $67.54 \%$ of males and only $32.43 \%$ of females were diagnosed with autism. Boys are at higher risk for autism than girls and a previous study has reported the average male: female ratio as 3.8:1. ${ }^{(15)}$ But certain studies have also reported that it may be greatly modified by cognitive impairment: and it may be close to 2:1 with mental retardation. ${ }^{(10)}$ In the same way, in the present study, all most all of the subjects were with certain degree of mental retardation and the prevalence of autism was 2.08 times higher in males than in females.

There is no one single unified theory that explains the etiology of autism. Autistic symptoms occur along a wide spectrum. ${ }^{(1)}$ Accordingly in the present study, frequency of autistic features in our study group was significantly different. The frequency of presence of different autistic 
features ranged from $20.27 \%$ to $97.29 \%$. However, among these autistic features, distorted speech, repetitive speech and tantrum to minor changes in the environment were observed in more than $90 \%$ of our study subjects (Table I).

Autism is a disorder of neural development characterized by impaired social interaction. Correspondingly, in several of our study subjects, failure to make eye contact, aloofness and tantrum to minor changes were noticed (Table I). Among these symptoms, tantrum to minor changes in the environment was observed in more than $97 \%$ of study subjects (Table I). Certain studies have noted that in children with mental retardation, autism is associated with aggression destruction of property and tantrum. ${ }^{(16)}$ Our study finding is in support of this view as, all the study subjects exhibiting tantrum to minor changes in the environment, were having intelligence quotients less than 70 .

Autism is also characterized by impaired communication. Symptoms of impaired communication observed in the present study were: distorted and repetitive speech in more than $90 \%$ of study subjects and delayed speech was observed in nearly $72 \%$ (Table I).

Autistic individuals display many forms of repetitive or restricted behavior. In our study subjects, repetitive or restricted behavior was not common in all the autistic subjects. However, self-injury was observed in $59.45 \%$ of study subjects.

M ental retardation is one of the observed comorbid state in autistic subjects. ${ }^{(17)}$ In our study, we compared the autistic features between subjects with IQ less than 50 with subjects having IQ above 50 . Among the autistic features compared, aloofness was significantly higher in subjects having IQ less than 50 compared to IQ above 50 (Table II). Apart from this higher proportion of subjects with poor interaction was observed in lower IQ group compared to higher IQ group (Table II).

Autism spectrum disorder is associated with epilepsy. ${ }^{(18-20)}$ Accordingly, $25.67 \%$ of our study subjects had the history of epilepsy. All of them had moderate to severe autism.
None of the mild autistic subjects had the history of epilepsy. Thus our study findings suggest that epilepsy is associated with severity of autism. Previous reports on comparison of epileptic comorbid state in autistic subjects reports that epilepsy is more common in females However, in the present study, $6(25 \%)$ females and 13 males $(26 \%)$ were with epilepsy.

In the present study, in autistic - epileptic group, proportion of subjects failing to make eye contact, not understanding humor and failing to identify strangers was significantly higher compared to non-epileptic autistic group (Table III). Making eye contact, understanding humor and identifying strangers are the normal social norms. Thus our study finding suggests that, presence of epilepsy adversely influence the social behavior in autistic subjects.

It is reported that, unusual eating behavior occurs in about three-quarters of children with autism spectrum disorder and selectivity of food is the most common problem. ${ }^{(16)}$ Similarly in our autistic subjects, selective food preference was observed in all the study subjects. Among these selective food items, a specific sweet item was observed in more than $75 \%$ of the autistic subjects.

Our study is with certain limitations. Prevalence of autism is done based on clustering sample rather community based. However, as our study subjects were drawn from all the special schools in different areas of our community it may roughly estimate the prevalence of autism in this region. Secondly, we devised a scoring system to grade the severity of autism. But for lack of suitable scale for comparison we could not completely standardize the scoring system. Thus further studies may be required in assessing the validity of the method followed in this study in grading severity of autism.

Thus based on our study findings it could be concluded that, tantrum to minor changes, distorted and repetitive speech are the most common autistic features. Risk of autism is 2.08 times higher in males compared to females. Aloofness and poor interaction symptoms are higher in autistic subjects with lower intelligence quotients. Epilepsy is associated with higher number of autism symptoms. The 
frequency of certain autistic features namely fail to make eye contact, unable to identify strangers and fail to understand humor is higher in epileptic autistic subjects.

Table I. Proportion of subjects with different autistic features in Study Group and according to gender.

\begin{tabular}{|c|c|c|c|}
\hline Autistic features & $\begin{array}{c}\text { study group ( } \mathbf{n}=\mathbf{7 4} \text { ) } \\
\text { (males and females together) }\end{array}$ & $\begin{array}{l}\text { Males group } \\
\qquad(\mathrm{n}=50)\end{array}$ & $\begin{array}{l}\text { Females group } \\
\qquad(n=24)\end{array}$ \\
\hline Made no eye contact & $44(59.45 \%)$ & $27(54 \%)$ & $17(70.83 \%)^{\mathrm{NS}}$ \\
\hline Indifferent to affection & $50(67.56 \%)$ & $35(70 \%)$ & $15(62.5 \%)^{\mathrm{NS}}$ \\
\hline Aloofness & $54(72.97 \%)$ & $34(68 \%)$ & $20(83.33 \%)^{\mathrm{NS}}$ \\
\hline Do not Identifies strangers & $24(32.43 \%)$ & $14(28 \%)$ & $10(41.66 \%)^{\mathrm{NS}}$ \\
\hline Delayed speech & $53(71.62 \%)$ & $33(66 \%)$ & $20(83.33 \%)^{\mathrm{NS}}$ \\
\hline Do not understands humor & $33(44.59 \%)$ & $24(48 \%)$ & $9(37.5 \%)^{\mathrm{NS}}$ \\
\hline Do not Plays with siblings $\&$ parents & $15(20.27 \%)$ & $11(22 \%)$ & $4(16.66 \%)^{N S}$ \\
\hline Injures oneself & $44(59.45 \%)$ & $31(62 \%)$ & $13(54.16 \%)^{\mathrm{NS}}$ \\
\hline Distorted speech & $67(90.54 \%)$ & $45(90 \%)$ & $22(91.66 \%)^{\mathrm{NS}}$ \\
\hline Repetitive speech & $70(94.59 \%)$ & $48(96 \%)$ & $22(91.66 \%)^{\mathrm{NS}}$ \\
\hline Tantrums to minor changes & $72(97.29 \%)$ & $49(98 \%)$ & $23(95.83 \%)^{\mathrm{NS}}$ \\
\hline Sits in odd posture & $54(72.97 \%)$ & $36(72 \%)$ & $18(75 \%)^{\mathrm{NS}}$ \\
\hline Delayed milestones & $58(78.37 \%)$ & $38(76 \%)$ & $20(83.33 \%)^{\mathrm{NS}}$ \\
\hline Sticks to odd objects & $54(72.97 \%)$ & $24(48 \%)$ & $20(83.33 \%)^{\mathrm{NS}}$ \\
\hline $\begin{array}{r}\text { Interaction- good } \\
\text { average } \\
\text { poor }\end{array}$ & $\begin{array}{c}4(5.4 \%), \\
42(56.75 \%) \\
28(37.83 \%)\end{array}$ & $\begin{array}{c}4(8 \%) \\
26(35.13 \%) \\
20(27.02 \%)\end{array}$ & $\begin{array}{c}0 \\
16(66.66 \%) \\
8(33.33 \%)^{\mathrm{NS}}\end{array}$ \\
\hline
\end{tabular}

Table II. Comparison of autistic features between subjects with below 50 and above 50 intelligent quotients.

\begin{tabular}{|l|c|c|}
\hline Autistic features & $\mathbf{2 6 - 5 0 ~ I Q ~ g r o u p ~ ( n ~ = ~ 4 8 ) ~}$ & $\mathbf{5 1 - 8 0}$ IQ group (n = 26) \\
\hline Do not make eye contact & 30 & $\mathbf{1 4}$ \\
\hline Indifferent to affection & 36 & 14 \\
\hline Aloof & $41^{*}$ & 13 \\
\hline Do not Identifies strangers & 18 & 6 \\
\hline Delayed speech & 35 & 18 \\
\hline Do not play with parents and siblings & 9 & 6 \\
\hline Do not understand humor & 20 & 13 \\
\hline Injures oneself & 30 & 14 \\
\hline Distorted speech & 45 & 22 \\
\hline Repetitive speech & 44 & 26 \\
\hline Tantrum to minor changes & 47 & 25 \\
\hline Holds odd objects & 34 & 20 \\
\hline Interaction - good & 3 & 1 \\
\hline Interaction-average & 22 & 20 \\
\hline Interaction- poor & $23^{* *}$ & 5 \\
\hline Delayed mile-stones & 40 & 18 \\
\hline
\end{tabular}

$* P \varangle 0.002$ Fisher exact test 2 sided; $* *$ Pearson Chi-square 6.720, $p=0.035$; Likelihood ratio 7.041, $p=0.030$; The average age of 26-50 IQ group was $14.51 \pm 6.14(n=50)$, the average age of 51-78 IQ group was $17.56 \pm 7.28(n=24)$ 
Table III. Prevalence of autistic symptoms in epileptic and non-epileptic study subjects.

\begin{tabular}{|l|c|c|c|}
\hline Variables & $\begin{array}{c}\text { Epileptic autism } \\
\text { group ( } \mathbf{~ = 1 9 )}\end{array}$ & $\begin{array}{c}\text { Non-epileptic } \\
\text { autism group ( } \mathbf{n}=\mathbf{5 5})\end{array}$ & P value \\
\hline Do Not make eye contact & 15 & 29 & $0.044^{*}$ \\
\hline Aloofness & 16 & 38 & 0.201 \\
\hline Injures self & 12 & 32 & 0.634 \\
\hline Tantrums to minor changes & 19 & 53 & 0.104 \\
\hline Do not understands humor & 13 & 20 & $0.015^{* *}$ \\
\hline Sticks to odd objects & 16 & 38 & 0.201 \\
\hline Sits in odd posture & 15 & 39 & 0.496 \\
\hline Indifferent to affection & 16 & 34 & 0.07 \\
\hline Does not Identify strangers & 10 & 13 & $0.018^{* *}$ \\
\hline Delayed mile stones & 18 & 40 & $0.046^{*}$ \\
\hline Delayed speech & 14 & 39 & 0.817 \\
\hline
\end{tabular}

* Significant at $\mathrm{P} \varangle 0.05 ; * *$ significant at $\mathrm{p} \varangle 0.02$

\section{References :}

1. Wing L, Gould J. (Severe impairments of social interaction and associated abnormalities in children: epidemiology and classification. J Autism Dev Disord 1979; 9: 11-29.

2. Karande S. Autism: a review for family physicians. Indian J Med Sci 2006; 60:206-15

3. Levy SE, M andell DS, Schultz R.T. Autism. Lancet 2009; 374: 1627-38.

4. London $E$. The role of the neurobiologist in redefining the diagnosis of autism. Brain Pathol 2007; 17: 408-411.

5. Baird G, Cass H, Slonims V. Diagnosis of autism. BMJ 2003; 327, 488-93.

6. Myers SM, Johnson CP, American Academy of Pediatric Council on Children with Disabilities. Management of children with autism spectrum disorders. Pediatrics 2007; 120: 1162-82.

7. Stefanatos GA. Regression in autistic spectrum disorders. Neuropsychol Rev. 2008; 18:305-19.

8. Filipek PA, Accardo PJ, Baranek GT et al. The screening and diagnosis of autistic spectrum disorders. J Autism Dev Disord 1999; 29: 439-84.

9. Shattuck PT, Durkin M, Maenner $M$, et al. Timing of identification among children with an autism spectrum disorder: findings from a population-based surveillance study. J Am Acad Child Adolesc Psychiatry 2009; 48: 474-83.

10. Newschaffer CJ, Croen LA, Daniels J, et al. The epidemiology of autism spectrum disorders. Annu Rev Public Health 2007; 28: 235-58.

11. Mash, Bakley. Child Psychopathology. New York: The Guilford Press, 2003: 409-54.
12. Barbaresi WJ, Katusic SK, Colligan RC, et al. The incidence of autism in Olmsted County, Minnesota, 1976-1997: results from a populationbased study. Arch Pediatr Adolesc M ed. 2005; 159: 37- 44.

13. American Psychiatric Association. Diagnostic and Statistical M anual of Mental Disorders, 4th ed. rev. American Psychiatric Association: Washington, DC, 2000.

14. Dawson M , M ottron L, Gernsbacher M A. Learning in autism. In: Byrne $J \mathrm{H}$, ed. Learning and M emory: A Comprehensive Reference. Academic Press, 2008.

15. Fombonne E. The epidemiology of autism: A review. Psychol Med 1999; 29: 769-86.

16. Dominick KC, Davis NO, Lainhart J, et al. Atypical behaviors in children with autism and children with a history of language impairment. Res DevDisabil. 2007; 28:145-62.

17. Rapin I. Autism. N EnglJ Med 1997; 337:97-104.

18. Levisohn PM. The autism-epilepsy connection. Epilepsia 2007; 48: 33-35.

19. Gillberg C, Steffenburg S. Outcome and prognostic factors in infantile autism and similar conditions: a population-based study of 46 cases followed through puberty. J Autism Dev Disord 1987; 17: 273-87.

20. Wong V. Epilepsy in children with autistic spectrum disorder. J Child Neurol 1993; 8: 316-22.

21. Canitano R. Epilepsy in autism spectrum disorders. European Child \& Adolescent Psychiatry 2007; 16: 61-66. 